\title{
The targeted inhibition of Hsp90 by a synthetic small molecule, DPide offers an effective treatment strategy against TNBCs
}

\author{
YONG JIN OH, SUN YOU PARK and YOUNG HO SEO \\ College of Pharmacy, Keimyung University, Daegu 704-701, Republic of Korea
}

Received September 16, 2017; Accepted January 25, 2018

DOI: $10.3892 /$ or.2018.6250

\begin{abstract}
Triple-negative breast cancers (TNBCs) are the most aggressive and metastatic subtype of breast cancers and exhibit poor clinical outcome due to the lack of drug target receptors such as estrogen receptors (ER), progesterone receptors (PR), and human epidermal growth factor receptor 2 (Her2). The limited effectiveness of therapeutic options and the poor prognosis of TNBC patients emphasize the urgent need for identifying new therapeutic agents. In this regard, heat shock protein 90 (Hsp90) has emerged as a promising therapeutic target for the treatment of TNBCs. Hsp90 is a molecular chaperone that regulates the folding, stability, and function of many oncogenic proteins. Hence, the inhibition of Hsp90 chaperone function leads to a simultaneous blockage of multiple signaling pathways in the proliferation and survival of cancers. In the present study, we performed the design, synthesis, and biological evaluation of Hsp90 inhibitors and found that a synthetic small molecule, DPide exerted a potent anticancer activity against TNBC cell line, MDA-MB-231 and non-small cell lung cancer (NSCLC) cell line, $\mathrm{H} 1975$ with $\mathrm{GI}_{50}$ values of 0.478 and $1.67 \mu \mathrm{M}$, respectively. Soft-agar colony formation assay also revealed that DPide suppressed the anchorage-independent growth of MDA-MB-231 cells. Western blot analysis indicated that the treatment of MDA-MB-231 cells with DPide induced the proteasomal degradation of EGFR, Her2, Met, Akt, c-Raf, and $\mathrm{Cdk} 4$ and the consequent cleavage of PARP, leading to apoptotic cell death. DPide also inhibited the migration and MMP9 activity of MDA-MB-231 cells, suggesting that the metastatic potential of TNBCs could be suppressed by DPide. Collectively, DPide offers an effective therapeutic option for the treatment TNBCs.
\end{abstract}

Correspondence to: Professor Young Ho Seo, College of Pharmacy, Keimyung University, 1095 Dalgubeoldaero, Daegu 704-701, Republic of Korea

E-mail: seoyho@kmu.ac.kr

Key words: triple-negative breast cancer, Hsp90, small molecule, DPide, metastasis

\section{Introduction}

Breast cancers are the most malignant and leading cause of cancer-related deaths in women worldwide (1). Among all breast cancers, triple-negative breast cancers (TNBCs) are the most aggressive, metastatic, and difficult to treat due to the lack of estrogen receptors (ER), progesterone receptors (PR), and human epidermal growth factor receptor 2 (Her2) (2). Accordingly, TNBCs exhibit a poorer clinical outcome compared to other breast cancer subtypes (3). Moreover, the molecular heterogeneity of TNBC increases the difficulty in improving survival rates. Despite the development of hormonal and HER2-targeted therapies, patients with TNBC rarely respond to these therapeutic options $(4,5)$. Thus, conventional chemotherapy such as the use of taxanes and anthracyclines still remains the mainstay for the treatment of TNBC patients (6,7). The poor prognosis of TNBC patients along with the limited effectiveness of therapeutic options necessitates the development of alternative therapeutic approaches for the treatment of TNBCs.

Heat shock protein 90 (Hsp90) is a molecular chaperone that regulates the folding, stability, and function of its substrate proteins, referred to as 'client' proteins $(8,9)$. These clients include epidermal growth factor receptor (EGFR), human epidermal growth factor receptor 2 (Her2), anaplastic lymphoma kinase (Alk), mesenchymal-epidermal transition factor (Met), protein kinase B (Akt), cyclin-dependent kinase 4 $(\mathrm{Cdk} 4)$, hypoxia inducible factor 1 (HIF-1 $\alpha$ ), and matrix metalloproteinase 9 (MMP9). Consequently, inhibition of the Hsp90 protein induces the degradation of these oncogenic proteins via the ubiquitin-proteasome pathway $(10,11)$ and results in a simultaneous disruption of multiple signaling pathways in the proliferation and survival of cancers $(12,13)$. Therefore, Hsp90 has emerged as a promising therapeutic target for the treatment of TNBCs (9).

Geldanamycin, a benzoquione ansamycin antibiotic was first identified as a natural product Hsp90 inhibitor in 1994 (14). Since then, numerous geldanamycin analogues such as 17-AAG, 17-DMAG, and IPI-504 were entered into clinical trials (15). Despite their clinical effects, geldanamycin analogues revealed several drawbacks in their clinical application such as formulation and toxicity issues (16). Hence, significant efforts have been directed towards improving drug-like properties and toxicities, resulting in diverse 
synthetic small molecule inhibitors. These Hsp90 inhibitors are divided into three major classes according to their core structures, purine, resorcinol, and benzamide. The purine class is designed by mimicking the ATP structure and includes PU-H71 (17), BIIB02 (18), and CUDC-305 (19) and the resorcinol class includes AT13387 (20), STA-9090 (21), and NVP-AUY922 (22). The benzamide class is another important class of Hsp90 inhibitors, including TAS-116 (23), XL888 (24), and SNX-5422 (25). Although a number of Hsp90 inhibitors have been entered into clinical trials, none of the Hsp90 inhibitors are clinically approved yet.

In our ongoing effort to develop potent Hsp90 inhibitors, we previously revealed that a small molecule, 6,7-dihydrothieno[3,2-c] pyridin-5(4H)-yl amide (DPide, 1) displays anticancer effects on cancer cells and this observation prompted us to direct our efforts toward evaluating the biological activity of DPide (1) and its analogue Oxo-DPide (2) against MDA-MB-231 TNBC cell line (26-28).

\section{Materials and methods}

Chemistry. All reagents and solvents were purchased from Sigma-Aldrich (Milwaukee, WI, USA) and Alfa Aesar (Haverhill, MA, USA), and used without further purification. All experiments dealing with moisture-sensitive compounds were carried out under an argon atmosphere. Concentration or solvent removal under reduced pressure was carried out using a rotary evaporator. Analytical thin layer chromatography was performed on precoated silica gel $\mathrm{F}_{254}$ TLC plates (Merck, Darmstadt, Germany) with visualization under UV light. Column chromatography was conducted under medium pressure on silica (Merck Silica Gel 40-63 $\mu \mathrm{m}$ ) or performed using a Biotage SP1 flash purification system with prepacked silica gel cartrides (Biotage AB, Uppsala, Sweden). NMR analyses were carried out using a JNM-ECZ500R spectrometer $(500 \mathrm{MHz})$ manufactured by JEOL, Ltd. (Tokyo, Japan). Chemical shifts were reported in parts per million ( $\delta$ ). The deuterium lock signal of the sample solvent was used as a reference, and coupling constants $(J)$ were given in hertz $(\mathrm{Hz})$. The splitting pattern abbreviations were as follows: s, singlet; $d$, doublet; $\mathrm{t}$, triplet; q, quartet; dd, doublet of doublets; $\mathrm{m}$, multiplet. The purities of all final compounds were confirmed to be higher than $95 \%$ by analytical HPLC performed with a dual pump Shimadzu LC-6AD system equipped with a VP-ODS C18 column (4.6x250 mm, $5 \mu \mathrm{m}$; Shimadzu Corporation, Kyoto, Japan).

Synthesis of 5-(2,4-Dihydroxy-5-isopropylbenzoyl)-5,6, 7,7a-tetrahydrothieno[3,2-c]pyridin-2(4H)-one (Oxo -Dpide, 2). A mixture of compound $2(0.20 \mathrm{~g}, 1.02$ mmol), 5,6,7,7a-tetrahydrothieno[3,2-c]pyridin-2(4H)-one hydrochloride $(0.29 \mathrm{ml}, 1.53 \mathrm{mmol})$, 1-ethyl-3-(3-dimethylaminopropyl) carbodiimide $(0.39 \mathrm{~g}, 2.04 \mathrm{mmol})$, and $N, N$-diisopropylethylamine $(0.36 \mathrm{ml}, 2.04 \mathrm{mmol})$ in $4 \mathrm{ml}$ of DMF was stirred under microwave irradiation at $80^{\circ} \mathrm{C}$ and $30 \mathrm{bar}$ for $3 \mathrm{~h}$. The mixture was concentrated under reduced pressure and purified by MPLC to afford Oxo-DPide (2) in $10 \%$ yield. $R_{f}=0.19$ (5:5 ethyl acetate: hexane). ${ }^{1} \mathrm{H}$ NMR (500 MHz, $\left.\mathrm{CD}_{3} \mathrm{OD}\right) \delta 7.02(\mathrm{~s}, 1 \mathrm{H}), 6.37$ (s, 1H), $5.32(\mathrm{~d}, J=14.5 \mathrm{~Hz}, 1 \mathrm{H}), 4.49-4.46(\mathrm{~m}, 1 \mathrm{H}), 3.79$ $(\mathrm{d}, J=14.5 \mathrm{~Hz}, 1 \mathrm{H}), 3.49(\mathrm{~s}, 1 \mathrm{H}), 3.25(\mathrm{t}, J=14.5 \mathrm{~Hz}, 1 \mathrm{H})$, 3.18-3.12 (m, 1H), 2.53-2.49 (m, 1H), 1.91-1.85 (m, 1H), 1.19 $(\mathrm{d}, J=6.5 \mathrm{~Hz}, 6 \mathrm{H})$. ESI MS $(m / e) 334.12[\mathrm{M}+1]^{+}$.

Cell culture \& materials. H1975 cells (from the ATCC, Manassas, VA, USA) (NSCLC) were grown in RPMI-1640 with L-glutamine supplemented with streptomycin $(500 \mathrm{mg} / \mathrm{ml})$, penicillin $(100 \mathrm{U} / \mathrm{ml})$, and $10 \%$ fetal bovine serum (FBS). Triple-negative breast cancer cells MDA-MB-231 (from the ATCC) were grown in DMEM high glucose, supplemented with streptomycin $(500 \mathrm{mg} / \mathrm{ml})$, penicillin $(100 \mathrm{U} / \mathrm{ml})$, and $10 \%$ fetal bovine serum (FBS). Cells were grown to confluence at $37^{\circ} \mathrm{C}$ in a humidified atmosphere with $5 \% \mathrm{CO}_{2}$. DPide was prepared following a previously reported procedure (26). For in vitro studies, DPide and geldanamycin (Alexis Biochemicals; Enzo Life Sciences, Inc., Farmingdale, NY, USA) were dissolved in DMSO. Antibodies for EGFR (1:1,000; rabbit anti-human mAb; cat. no. 4267) Her2 (1:1,000; rabbit anti-human mAb; cat. no. 2165), Met (1:1,000; rabbit anti-human mAb; cat no. 8198), Akt (1:1,000; rabbit anti-human pAb; cat. no. 9272) c-Raf (1:1,000; rabbit anti-human pAb; cat. no. 9422), Cdk4 (1:1,000; mouse anti-human mAb; cat. no. 2906), Hsp90 (1:1,000; rabbit anti-human pAb; cat. no. 4874), Hsp70 (1:1,000; rabbit anti-human pAb; cat. no. 4872), PARP (1:1,000; rabbit anti-human pAb; cat. no. 9542) and $\beta$-actin (1:1,000; rabbit anti-human $\mathrm{mAb}$; cat. no. 4970) were purchased from Cell Signaling Technology (Beverly, MA, USA). Anti-mouse (1:5,000; goat anti-mouse pAb; cat. no. sc-2005) and anti-rabbit antibodies (1:5,000; goat anti-rabbit pAb; cat. no. sc-2004) were purchased from Santa Cruz Biotechnology (Dallas, TX, USA).

Cell proliferation assay. $\mathrm{H} 1975$ cells $\left(2 \times 10^{3}\right.$ cells/well) were seeded in a 96-well plate. The medium volume was brought to $100 \mu \mathrm{l}$, and the cells were allowed to attach for $14 \mathrm{~h}$. The cells were then incubated with DPide or Oxo-DPide $(0.01,0.1$, $0.05,0.1,0.5,1,5,10,30,50,70$ and $100 \mu \mathrm{M})$ at $37^{\circ} \mathrm{C}$ with $5 \%$ $\mathrm{CO}_{2}$ for 3 days. MDA-MB-231 cells $\left(2 \times 10^{3}\right.$ cells/well $)$ were seeded in a 96-well plate, the medium volume was brought to $100 \mu \mathrm{l}$, and the cells were allowed to attach for $14 \mathrm{~h}$. The cells were then incubated with DPide $(0.01,0.1,1$ and $5 \mu \mathrm{M})$ at $37^{\circ} \mathrm{C}$ with $5 \% \mathrm{CO}_{2}$ for 1,2 , and 3 days. CellTiter 96 Aqueous One Solution reagent (Promega Corp., Madison, WI, USA) was added into each well following the manufacturer's instructions. The absorbance at $490 \mathrm{~nm}$ was read on the Tecan Infinite F200 Pro plate reader, and values were expressed as the percentage of the absorbance from cells incubated in DMSO alone.

Western blotting. After being treated with DPide $(0.05,0.1$, $0.5,1$, and $2 \mu \mathrm{M})$ or GA $(1 \mu \mathrm{M})$ for $24 \mathrm{~h}$, MDA-MB-231 cells were harvested and lysed in ice-cold lysis buffer $(25 \mathrm{mM}$ Tris- $\mathrm{HCl} \mathrm{pH}$ 7.6, $150 \mathrm{mM} \mathrm{NaCl}, 1 \% \mathrm{NP} 40,1 \%$ sodium deoxycholate, $0.1 \%$ SDS, $1 \mathrm{mM}$ phenylmethylsulfonyl fluoride). The $30 \mu \mathrm{g}$ of lysate per lane was separated by SDS-PAGE and transferred to a PVDF membrane (Bio-Rad Laboratories, Hercules, CA, USA). After being blocked with 5\% skim milk in TBS with $0.1 \%$ Tween-20 (TBS-T), the membrane was incubated with the corresponding antibodies in TBS-T at $4^{\circ} \mathrm{C}$ overnight. The proteins were visualized using an enhanced 
chemiluminescence (ECL) reagent according to the manufacturer's instructions (GE Healthcare, Pittsburgh, PA, USA).

Reverse-transcriptase PCR (RT-PCR). RT-PCR was performed using the RT-PCR kit (Bio-Rad Laboratories) following the manufacturer's protocol. Briefly, total RNA was extracted from cultured cells using TRIzol reagent (Thermo Fisher Scientific, Hampton, NH, USA), reverse transcribed, and then subjected to PCR. The following primers were used for the amplification of human Met, Akt, Cdk4, Hsp90 and $\beta$-actin: Met, 5'-AAGAGGGCATTTTGGTTGTG-3' (forward) and 3'-GATGATTCCCTCGGTCAGAA-5' (reverse); Akt, 5'-TTT TATTTCTCGGGTGCAT-3' (forward) and 3'-CATTTCCCT ACGTGAATCGG-5' (reverse); Cdk4, 5'-CCGAAGTTCTTC TGCAGTCC (forward) and 3'-AGGCAGAGATTCGCTTGT GT (reverse); Hsp90, 5'-GAGCAGTACGCTTGGGAGTC (forward) and 3'-CCAGATGGGCTTTGTTTTGT (reverse); $\beta$-actin, 5'-AGAAAATCTGGCACCACACC-3' (forward) and 3'-CCATCTCTTGCTCGAAGTCC-5' (reverse).

Colony formation assay. MDA-MB-231 cells ( $1 \times 10^{5}$ cells/well) were seeded in a 6 -well plate and treated with DPide $(0.1$ and $0.5 \mu \mathrm{M})$ at $37^{\circ} \mathrm{C}$ with $5 \% \mathrm{CO}_{2}$ for 21 days. After treatment, the medium removed and stained with $0.1 \%$ of crystal violet in $10 \%$ ethanol at room temperature for $30 \mathrm{~min}$. The image was acquired with an inverted phase contrast microscope (Olympus, Japan) using a 100X objective.

Wound healing assay. MDA-MB-231 cells ( $2 \times 10^{5}$ cells/well) were seeded in a 6-well plate, and the cells were allowed to attach for $24 \mathrm{~h}$. The $80 \%$ confluent cells were wounded with a linear scratch using a disposable $200-\mu 1$ micropipette tip. The cells were washed with medium to remove cell debris and covered with serum free medium containing DPide $(0.1$ and $0.5 \mu \mathrm{m}$ or GA $(1 \mu \mathrm{m})$. After being incubated for $24 \mathrm{~h}$, the migrated cells were determined under an inverted phase contrast microscope (Olympus, Tokyo, Japan) using a 100X objective.

Gelatin zymography assay. MDA-MB-231 (5x105 cells/well) cells were seeded in a 6-well culture plate and treated with DPide $(0.05,0.5$, and $1 \mu \mathrm{m}$ or GA $(1 \mu \mathrm{m})$ for $24 \mathrm{~h}$. Supernatants were collected and loaded on a $10 \%$ SDS-PAGE gel with gelatin $(0.2 \mathrm{mg} / \mathrm{ml})$. Following electrophoresis, the gels were washed for $40 \mathrm{~min}$ in $2.5 \%$ Triton X-100. After washing with deionized water, the gels were incubated for an additional for $72 \mathrm{~h}$ at $37^{\circ} \mathrm{C}$ in incubation buffer $(50 \mathrm{mM}$ Tris, $0.15 \mathrm{M} \mathrm{NaCl}$, $10 \mathrm{mM} \mathrm{CaCl} 2,0.05 \%$ sodium azide, $\mathrm{pH} 7.8)$. The gel was stained with staining solution (1\% Commassie Brilliant Blue $\mathrm{G}-250,5 \% \mathrm{MeOH}, 10 \%$ acetic acid). The number of pixels per band was used to determine the enzyme activity in each group. The gelatin zymography experiment was repeated three times with independent samples.

Fluorescence polarization (FP) assay. All fluorescence polarization experiments were conducted in 96-well, black, round-bottom plates using a microplate reader. For FP assay experiments, to each well, HFB buffer (20 mM HEPES pH 7.3, $50 \mathrm{mM} \mathrm{KCl,} 5 \mathrm{mM} \mathrm{MgCl} 2,20 \mathrm{mM} \mathrm{Na} \mathrm{MoO}_{4}, 0.01 \%$ $\mathrm{NP}-40$ ), $30 \mathrm{nM}$ recombinant Hsp90 $\alpha$ full length protein, $5 \mathrm{nM}$ fluorescein isothiocyanate labeled geldanamycin (GA-FITC) inhibitor, $0.1 \mathrm{mg} / \mathrm{ml}$ bovine globulin (BGG), $2 \mathrm{mM}$ 1,4-dithiothreitol (DTT) and inhibitors (0.001, 0.01, 0.1, 0.5, 1, 5, 10, 50 , and $100 \mu \mathrm{M})$ were added. All wells had a final volume of $100 \mu \mathrm{l}$ in the HFB buffer. The plates were incubated at $4^{\circ} \mathrm{C}$ for $14 \mathrm{~h}$. The polarization values in millipolarization units $(\mathrm{mP})$ were assessed at an excitation wavelength at $495 \mathrm{~nm}$ and an emission wavelength at $530 \mathrm{~nm}$. All experimental data were analyzed using Prism software (Graphpad Software, San Diego, CA, USA).

Molecular modeling. In silico docking of Oxi-DPide (1) or Oxi-DPide (2) with the 3D coordinates of the X-ray crystal structures of the $N$-terminal domain of human Hsp90 $\alpha$ (PDB code: 2XJX) was accomplished using the AutoDock program downloaded from the Molecular Graphics Laboratory of the Scripps Research Institute (La Jolla, CA, USA). In the docking experiments carried out, Gasteiger charges were placed on the X-ray structures of the $N$-terminal domain of Hsp90 along with Oxi-DPide (1) or Oxi-DPide (2) using tools from the AutoDock suite. A grid box centered on the $N$-terminal Hsp90 domain with definitions of $60 \times 60 \times 60$ points and $0.375 \AA$ spacing was chosen for ligand docking experiments. The docking parameters consisted of setting the population size to 150 , the number of generations to 27,000 , and the number of evaluations to $25,000,000$, while the number of docking runs was set to 100 with a cutoff of $1 \AA$ for the root-mean-square tolerance for the grouping of each docking run. The docking model of human Hsp90 $\alpha$ with Oxi-DPide (1) or Oxi-DPide (2) are depicted in Fig. 1 and the images were generated using PyMol1.3 (DeLano Scientific LLC, Palo Alto, CA, USA).

Statistical analysis. Statistical analysis was performed with the Student's t-test (two-tailed) using Prism GraphPad software. Differences with ${ }^{*} \mathrm{P}<0.05,{ }^{* *} \mathrm{P}<0.01,{ }^{* * *} \mathrm{P}<0.001$ were considered statistically significant. Data were represented as the mean \pm SD.

\section{Results}

Molecular docking and drug design. Our previous study indicated that DPide (1) strongly bound to the ATP-binding pocket in the $N$-terminal domain of Hsp90 $\alpha$ (Fig. 1A) (26). The resorcinol ring and the carbonyl group of DPide (1) formed the hydrogen bonding interactions with Asp93, Thr184, and conserved water molecules, while the isopropyl group of DPide (1) was imbedded into the hydrophobic cavity formed by Leu107, Phe138, and Val186. The 6,7-dihydrothieno[3,2-c] pyridine-5(4H)-yl moiety of DPide (1) was nicely positioned in the entry region composed of Asp54, Ala55, and Ile96. The docking pose of DPide (1) suggested that installing a carbonyl group on DPide (1) may form an additional hydrogen bonding interaction with the carboxylic acid side chain of Asp54. Therefore, we rationally designed Oxo-DPide (2) having an extra carbonyl group adjacent to the sulfur atom and performed the docking simulation shown in Fig. 1B. To experimentally examine whether Oxo-DPide (2) can form an additional hydrogen bonding interaction with the carboxylic acid side chain of Asp54, we first commenced the synthesis of DPide (1) and Oxo-DPide (2). 


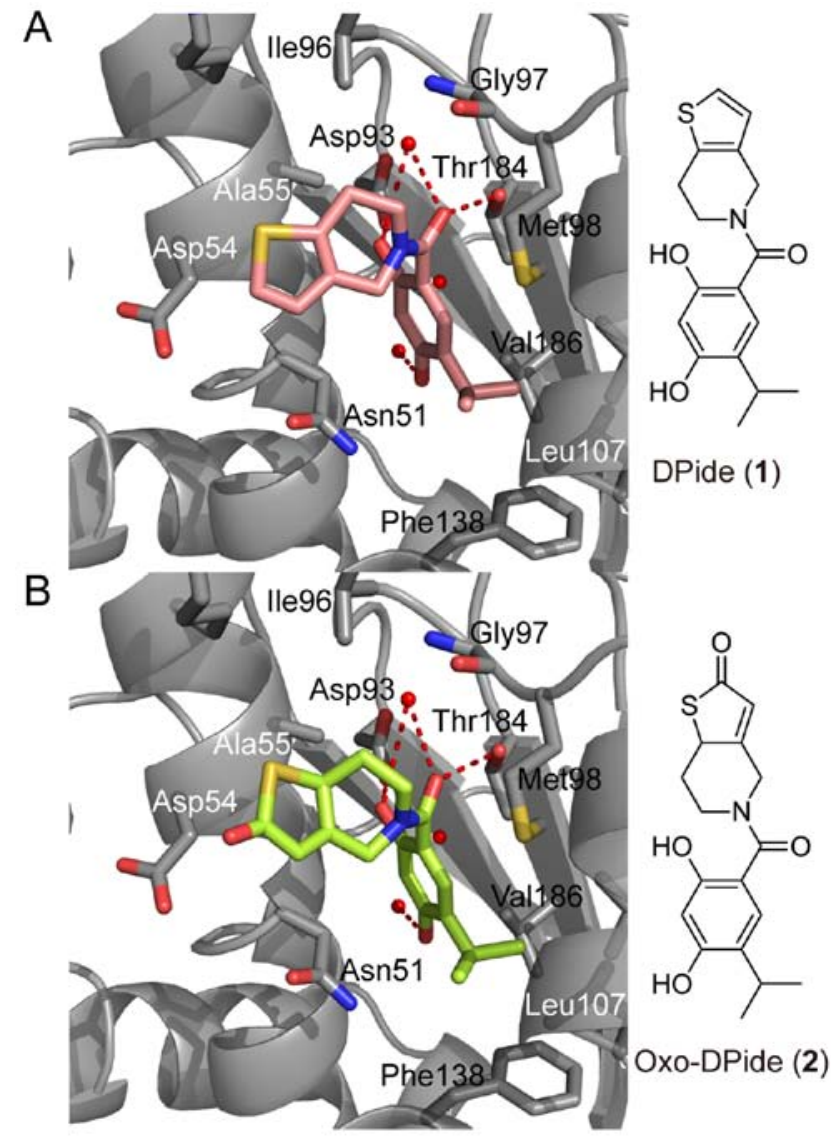

Figure 1. Molecular docking model of (A) DPide and (B) Oxo-DPide bound in the ATP-binding pocket of human Hsp90 (PDB code: 2XJX). The carbon atoms of DPide (1) and Oxo-DPide (2) are shown in pink and green, respectively. The oxygen, nitrogen, and sulfur atoms are shown in red, blue, and yellow, respectively. The side chains of the binding site are labeled with their residue name, the water molecules are shown as red spheres, and the hydrogen bonds are shown as red dashed lines. The docking poses of DPide (1) and Oxo-DPide (2) are visualized using PyMOL1.3.

Chemistry. DPide (1) was synthesized following a previously reported procedure (Fig. 2) (26). Briefly, the amide coupling reaction of carboxylic acid 3 with 4,5,6,7-tetrahydrothieno[3,2-c] pyridine (4) using EDC afforded DPide (1) in 52\% yield. Similarly, Oxo-DPide (2) was obtained by the reaction of carboxylic acid 3 with commercially available compound 5 using EDC, HOBt, and DIPEA in DMF under microwave irradiation at $80^{\circ} \mathrm{C}$ for $3 \mathrm{~h}$ in $10 \%$ yield.

Comparative Hsp90 binding affinity and anti-proliferative activity of DPide and Oxo-DPide. With DPide and Oxo-DPide in hand, we first assessed the direct binding affinity of DPide and Oxo-DPide to human Hsp90 $\alpha$ with a fluorescence piolarization (FP) assay in which FITC-labeled geldanamycin was used as a fluorescence probe. As shown in Fig. 3A and Table I, DPide directly bound to the ATP-binding pocket of Hsp90 $\alpha$ with an $\mathrm{IC}_{50}$ value of $33.3 \mathrm{nM}$, which was more potent than Oxo-DPide $\left(\mathrm{IC}_{50}=73.7 \mathrm{nM}\right)$. We next explored the anti-proliferative effect of DPide and Oxo-DPide on H1975 and MDA-MB-231 cancer cell lines. Consistent with the result from the FP assay, DPide displayed very potent anti-proliferative activity against H1975 and MDA-MB-231 cells with $\mathrm{GI}_{50}$ values of 0.478 and $1.67 \mu \mathrm{M}$ respectively, while Oxo-DPide exerted less efficient potency
Table I. Inhibitory activity against $\mathrm{Hsp} 90 \alpha$ and H1975 cancer cells.

\begin{tabular}{lccc}
\hline Compound & $\begin{array}{c}\mathrm{Hsp90} \alpha(\mathrm{FP})^{\mathrm{a}} \\
\left(\mathrm{IC}_{50} ; \mathrm{nM}\right)\end{array}$ & $\begin{array}{c}\mathrm{H} 1975^{\mathrm{b}} \\
\left(\mathrm{GI}_{50} ; \mu \mathrm{M}\right)\end{array}$ & $\begin{array}{c}\mathrm{MDA}^{2} \mathrm{MB}-231^{\mathrm{b}} \\
\left(\mathrm{GI}_{50} ; \mu \mathrm{M}\right)\end{array}$ \\
\hline DPide (1) & 33.3 & 0.478 & 1.67 \\
Oxo-DPide (2) & 73.7 & 20.7 & 35.8 \\
\hline
\end{tabular}

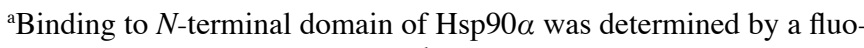
rescence polarization (FP) assay. ${ }^{\mathrm{b}} \mathrm{GI}_{50}$ values were obtained after the treatment of cells for $72 \mathrm{~h}$.

against $\mathrm{H} 1975$ and MDA-MB-231 cells with $\mathrm{GI}_{50}$ values of 20.7 and $35.8 \mu \mathrm{M}$ (Fig. 3B and Table I). Due to the higher potency of DPide than Oxo-DPide towards Hsp90 $\alpha$ as well as the two cancer cell lines, we decided to further investigate the biological activity of DPide but not Oxo-DPide against TNBCs.

DPide significantly inhibits the proliferation of $M D A-M B-231$ cells. To examine the anticancer activity of DPide against MDA-MB-231 cells, we first evaluated the dose- and time-dependent effect of DPide on the growth of MDA-MB-231 cells. MDA-MB-231 cells were treated with DPide at various concentrations $(0.01,0.1,1$, and $5 \mu \mathrm{M})$ for 1,2 , and 3 days and the cell viability was determined using an MTS assay (Fig. 4A). The cell viability assay revealed that DPide afforded very potent cellular efficacy against MDA-MB-231 cells in a dose- and time-dependent manner. Notably, the exposure of cells with DPide $(0.01,0.1,1$, and $5 \mu \mathrm{M})$ for 1 day displayed only a minimal effect on cell viability.

Anchorage-independent cell growth is a hallmark of oncogenic transformation and considered as a key metastatic potential for malignant cancer cells to proliferate away from their site of origin. Accordingly, we investigated the effect of DPide on the anchorage-independent cell growth and the soft-agar colony formation assay revealed that the treatment of cells with $0.5 \mu \mathrm{M}$ DPide inhibited the anchorage-independent growth of MDA-MB-231 cells, indicating that the metastatic potential of MDA-MB-231 cells could be suppressed by DPide (Fig. 4B).

DPide inhibits the chaperone function of Hsp9O and downregulated Hsp90 client proteins via the ubiquitin-proteasomal pathway. To uncover the underlying mechanism of DPide, we next analyzed the effect of DPide on the expression of Hsp90 client proteins in MDA-MB-231 cells. Hsp90 is well-known for maintaining the stability of EGFR, Her2, Met, Akt, c-Raf, and $\mathrm{Cdk} 4$. Thus, the inhibition of Hsp90 results in the degradation of these client proteins via the ubiquitin-proteasome pathway. As shown Fig. 5A, the exposure of cells to DPide induced a significant reduction of EGFR, Her2, Met, Akt, c-Raf, and Cdk4 in a dose-dependent manner, consequently leading to the cleavage of PARP. In contrast, DPide increased the cellular level of Hsp70 and Hsp90 proteins, upregulation of which is a cellular hallmark of Hsp90 inhibition. The expression of non-Hsp90-dependent protein, $\beta$-actin, remained 
<smiles>CC(C)c1cc(C(=O)O)c(O)cc1O</smiles>

3<smiles>CC(C)c1cc(C(=O)O)c(O)cc1O</smiles>

3
4<smiles>O=C1C=C2CNCCC2S1</smiles>

5<smiles>CC(C)c1cc(C(=O)N2CCc3sccc3C2)c(O)cc1O</smiles>

DPide (1)

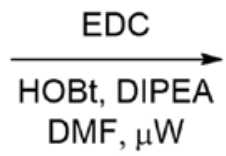

Figure 2. Synthesis of DPide (1) and Oxo-DPide (2).

A

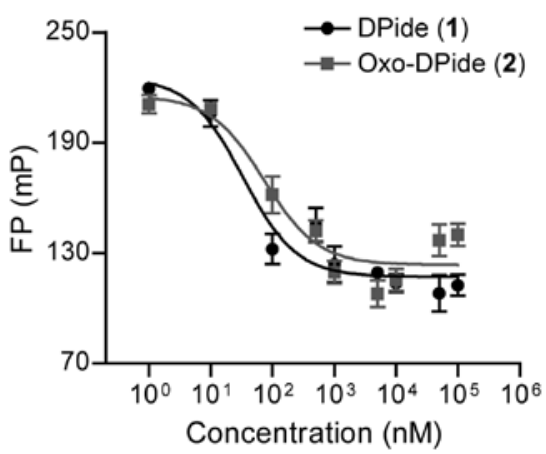

B

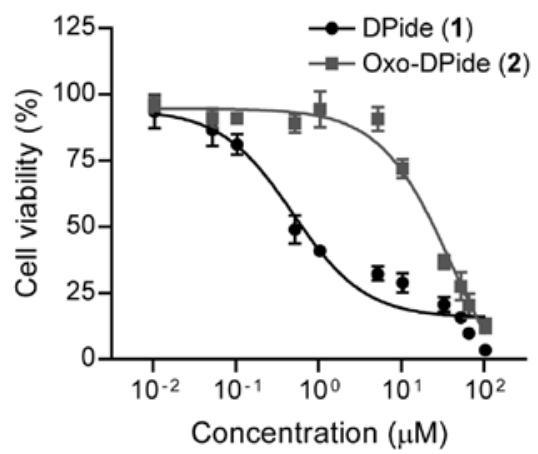

Figure 3. Comparative in vitro assays of DPide and Oxo-DPide. (A) Binding affinity to the ATP-binding pocket of Hsp90 $\alpha$ was determined using a fluorescence polarization (FP) assay after being incubated for $14 \mathrm{~h}$. (B) Anti-proliferative effect of DPide and Oxo-DPide on H1975 non-small cell lung cancer cells (NSCLC). Cells were incubated with the indicated concentrations of DPide and Oxo-DPide for 3 days and cell viability was assessed by MTS assay. Data are presented as the mean $\pm \mathrm{SD}(\mathrm{n}=4)$.

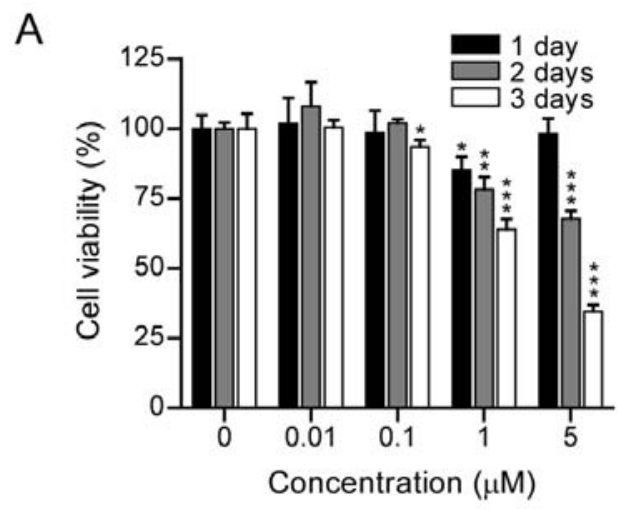

B

DMSO

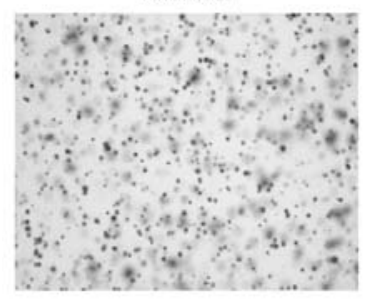

$0.1 \mu \mathrm{M}$ DPide

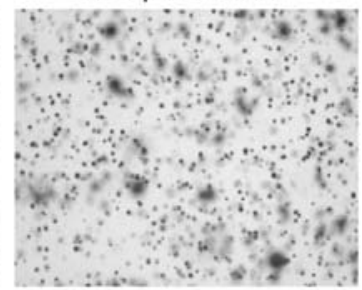

$0.5 \mu \mathrm{M}$ DPide

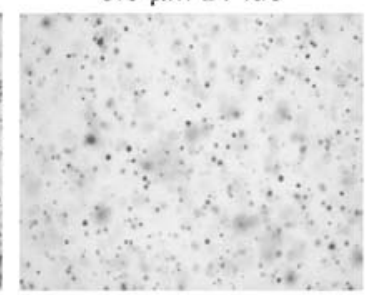

Figure 4. DPide inhibits the proliferation of MDA-MB-231 cells. (A) Dose- and time-dependent effect of DPide on the proliferation of MDA-MB-231 cells Cells were incubated with the indicated concentrations of DPide for 1,2, and 3 days and cell viability was assessed by MTS assay. Data are presented as the mean $\pm \mathrm{SD}(\mathrm{n}=4) ;{ }^{*} \mathrm{P}<0.05,{ }^{* *} \mathrm{P}<0.01,{ }^{* * * *} \mathrm{P}<0.001$ represent significant differences compared with the DMSO control. (B) Colony forming capability was determined by colony formation assay in MDA-MB-231 cells after being treated with the indicated concentrations of DPide for 3 weeks. 

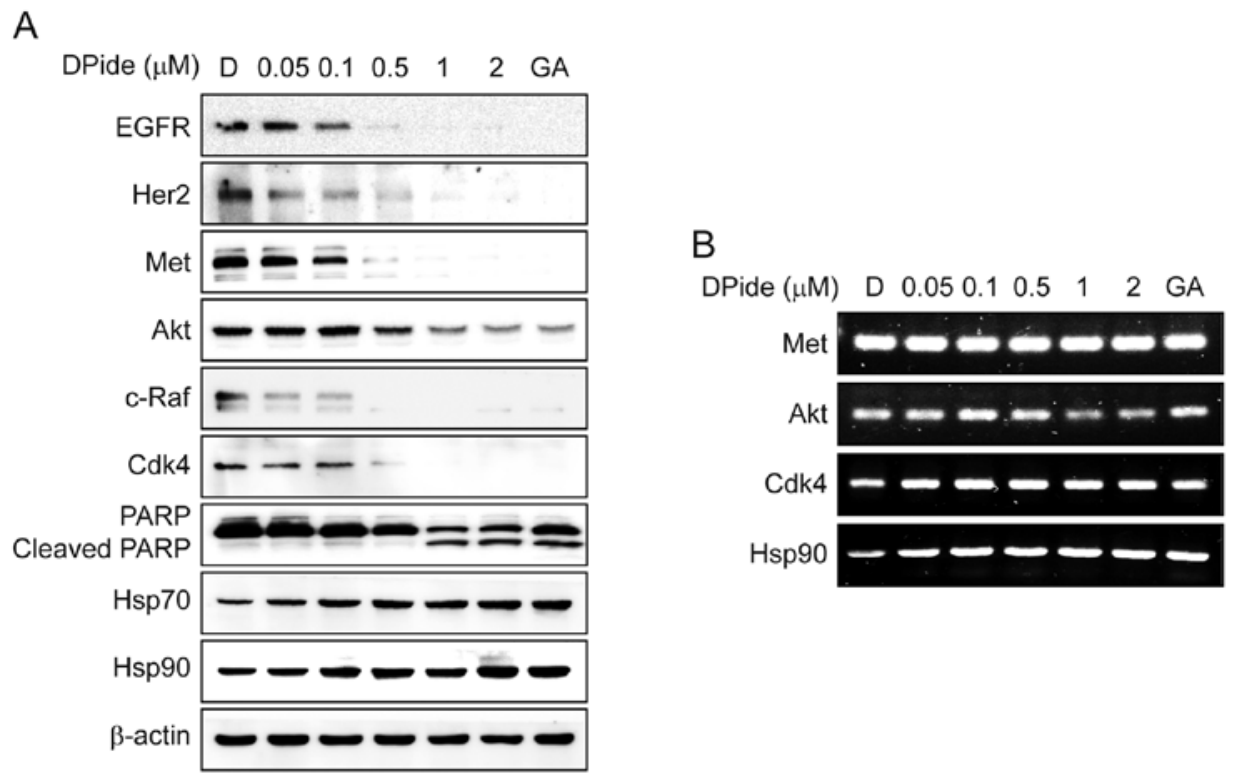

Figure 5. DPide inhibits the chaperone function of Hsp90 and induces the degradation of client proteins. (A) MDA-MB-231 cells were treated with the indicated concentrations of DPide for $24 \mathrm{~h}$ and the expression of EGFR, Her2, Met, Akt, c-Raf, Cdk4, PARP, Cleaved PARP, Hsp70, Hsp90, and $\beta$-actin was analyzed using western blotting. Geldanamycin $(\mathrm{GA}, 1 \mu \mathrm{M})$ and DMSO (D, $0.5 \%)$ were employed as a positive and a negative control, respectively. (B) Effect of DPide on the transcriptional levels of Met, Akt, Cdk4, and Hsp90 were assessed by semi-quantitative RT-PCR. MDA-MB-231 cells were treated with indicated concentrations of DPide for $24 \mathrm{~h}$. Total RNA was isolated from the cells, reverse-transcribed to cDNA, and then assessed by semi-quantitative RT-PCR Geldanamycin $(\mathrm{GA}, 1 \mu \mathrm{M})$ and DMSO $(\mathrm{D}, 0.5 \%)$ were employed as a positive and a negative control, respectively.

A

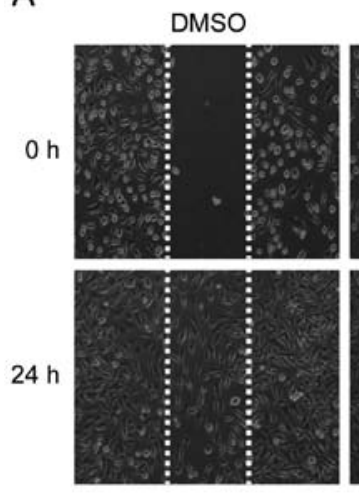

B

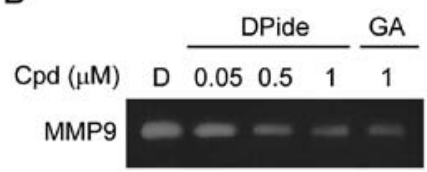

$0.1 \mu \mathrm{M}$ DPide
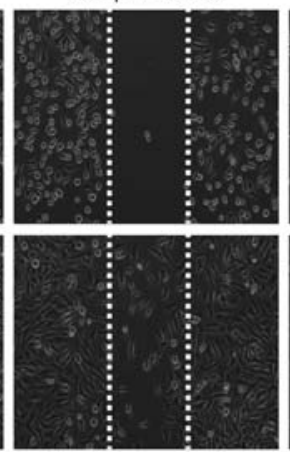

C
$1 \mu \mathrm{M} \mathrm{GA}$
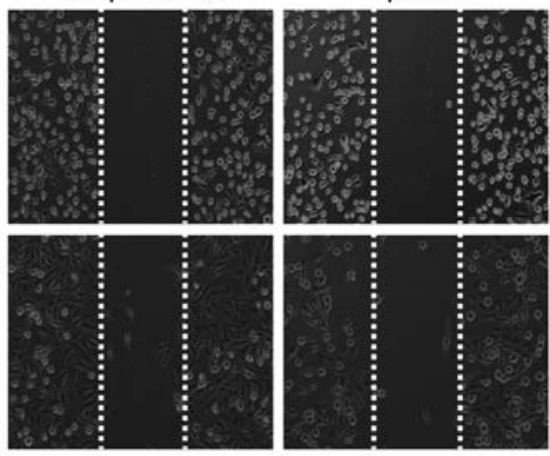

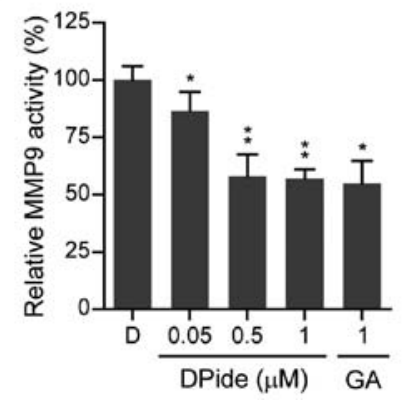

Figure 6. DPide impairs the cell migration and MMP9 activity in MDA-MB-231 cells. (A) Effect of DPide on the migration of MDA-MB-231 cells. After being scratched, MDA-MB-231 cells were incubated with the indicated concentrations of DPide for $24 \mathrm{~h}$. Images of the wounded monolayer were captured at 0 and $24 \mathrm{~h}$. (B) MDA-MB-231 cells were incubated with the indicated concentrations of DPide for $24 \mathrm{~h}$ and the proteolytic activity of MMP9 was determined by gelatin zymography assay. (C) Bar graphs represent the relative MMP9 activity. Data are presented as the mean $\pm \mathrm{SD}\left(\mathrm{n}=3\right.$ ); ${ }^{*} \mathrm{P}<0.05$, ${ }^{* *} \mathrm{P}<0.01$ represent a significant difference compared with the DMSO control.

unchanged as expected. To further clarify the mechanism of DPide in detail, we next assessed the mRNA levels of Met, Akt, Cdk4, and Hsp90 by semi-quantitative RT-PCR (Fig. 5B).
As expected, DPide did not significantly alter the mRNA levels of Met, Akt, and Cdk4, indicating that the downregulation of those protein levels occurred via proteasomal degradation but 
not transcriptional regulation. In contrast, DPide treatment increased the mRNA level of Hsp90 in a dose-dependent manner, in that inhibition of $\mathrm{Hsp} 90$ chaperone function by DPide induced proteotoxic stress, activated HSF1, and transcriptionally expressed chaperone proteins such as Hsp90, Hsp70, Hsp47, and Hsp27 by feedback mechanism (29). Collectively, these results demonstrated that DPide inhibited the chaperone function of Hsp90 and downregulated Hsp90 client proteins via the ubiquitin-proteasomal pathway.

DPide inhibits the migration and MMP9 activity of MDA-MB-231 cells. MDA-MB-231 cells have a mesenchymal phenotype and are highly aggressive metastatic breast cancer cells. An increase of mobility has been associated with the metastatic potential of cancer cells. To explore the anti-metastatic activity of DPide, we next examined the effect of DPide on the mobility of MDA-MB-231 cells. Wounds were first formed by scratching the cell monolayer with a pipette tip and wound closure of MDA-MB-231 cells in the presence or absence of DPide was assessed by counting the number of cells that had infiltrated the wounded area after $24 \mathrm{~h}$. As shown in Fig. 6A, treatment of cells with 0.1 and $0.5 \mu \mathrm{M}$ of DPide for $24 \mathrm{~h}$ significantly inhibited the migration of MDA-MB-231 cells compared to the DMSO control. Thus, the in vitro wound-healing migration assay revealed that DPide inhibited the migration of MDA-MB-231 cells.

Matrix metalloproteinases (MMPs) are a group of zinc-dependent proteases that are involved in the degradation and remodelling of the extracellular matrix (ECM). By degrading the matrix, MMPs provide physical space within the matrix for tumor growth, invasion, and metastasis. It has been reported that MMP9 is secreted by various types of malignant cancer cells and contributes to cancer metastasis by breaking down various EMC molecules, which allows metastatic cancer cells to be more invasive (30). Therefore, we next investigated the effect of DPide on MMP9 activity by performing gelatin zymography. As shown in Fig. 6B and C, DPide significantly suppressed MMP9 activity in MDA-MB-231 cells in a dose-dependent manner. Treatment of cells with $0.05,0.5$, and $1 \mu \mathrm{M}$ of DPide decreased MMP9 activity by 14,42 , and $43 \%$, compared to DMSO control, respectively. Collectively the results clearly indicated that DPide inhibited the migration of MDA-MB-231 cells and suppressed MMP9 activity of MDA-MB-231 cells.

\section{Discussion}

In the present study, the design, synthesis, and biological evaluation of Hsp90 inhibitors DPide and Oxo-DPide were described. Our results demonstrated that DPide more strongly bound to the $N$-terminal domain of $\operatorname{Hsp} 90 \alpha\left(\mathrm{IC}_{50}=33.3 \mathrm{nM}\right)$ than Oxo-DPide $\left(\mathrm{IC}_{50}=73.7 \mathrm{nM}\right)$ in the FP assay. Moreover, the FP enzyme affinity of DPide agreeably translated into satisfactory cellular activity with $\mathrm{GI}_{50}$ values of 0.478 and $1.67 \mu \mathrm{M}$ against H1975 and MDA-MB-231 cells, respectively. In contrast, Oxo-DPide inhibited the proliferation of H1975 and MDA-MB-231 cells with GI $_{50}$ values of 20.7 and $35.8 \mu \mathrm{M}$, respectively. The treatment of MDA-MB-231 cells with DPide led to the degradation of EGFR, Her2, Met, Akt, c-Raf, and Cdk4 and the consequent cleavage of PARP in a dose-dependent manner. In contrast, the treatment of MDA-MB-231 cells with DPide upregulated the protein level of Hsp70 and Hsp90. RT-PCR experiments revealed that the exposure of MDA-MB-231 cells with DPide did not alter the mRNA levels of Met, Akt, and Cdk4, suggesting that the downregulation of Hsp90 client proteins was associated with proteasomal degradation but not transcriptional downregulation. DPide efficiently suppressed the migration and MMP9 activity of MDA-MB-231 cells in a dose-dependent manner. Overall, these findings strongly support that a synthetic small molecule, DPide offers an effective treatment strategy against TNBCs.

\section{Acknowledgements}

The present study was supported by the Bisa Research Grant of Keimyung University in 2015.

\section{Competing interests}

The authors declare thay they have no competing interests.

\section{References}

1. Jemal A, Bray F, Center MM, Ferlay J, Ward E and Forman D: Global cancer statistics. CA Cancer J Clin 61: 69-90, 2011.

2. Anders $C$ and Carey LA: Understanding and treating triple-negative breast cancer. Oncology (Williston Park) 22: 1233-1243, 2008.

3. Yadav BS, Sharma SC, Chanana P and Jhamb S: Systemic treatment strategies for triple-negative breast cancer. World J Clin Oncol 5: 125-133, 2014.

4. Gajria D and Chandarlapaty S: HER2-amplified breast cancer: Mechanisms of trastuzumab resistance and novel targeted therapies. Expert Rev Anticancer Ther 11: 263-275, 2011.

5. Garcia-Becerra R, Santos N, Diaz L and Camacho J: Mechanisms of resistance to endocrine therapy in breast cancer: Focus on signaling pathways, miRNAs and genetically based resistance. Int J Mol Sci 14: 108-145, 2012.

6. Gradishar WJ, Anderson BO, Balassanian R, Blair SL, Burstein HJ, Cyr A, Elias AD, Farrar WB, Forero A, Giordano SH, et al: NCCN guidelines insights breast cancer, version 1.2016. J Natl Compr Canc Netw 13: 1475-1485, 2015.

7. Schiff R, Massarweh S, Shou J and Osborne CK: Breast cancer endocrine resistance: How growth factor signaling and estrogen receptor coregulators modulate response. Clin Cancer Res 9: 447S-454S, 2003.

8. Sankhala KK, Mita MM, Mita AC and Takimoto CH: Heat shock proteins: A potential anticancer target. Curr Drug Targets 12: 2001-2008, 2011

9. Whitesell L and Lindquist SL: HSP90 and the chaperoning of cancer. Nat Rev Cancer 5: 761-772, 2005.

10. da Silva VC and Ramos $\mathrm{CH}$ : The network interaction of the human cytosolic $90 \mathrm{kDa}$ heat shock protein Hsp90: A target for cancer therapeutics. J Proteomics 75: 2790-2802, 2012.

11. Zhang $\mathrm{H}$ and Burrows $\mathrm{F}$ : Targeting multiple signal transduction pathways through inhibition of Hsp90. J Mol Med (Berl) 82: 488-499, 2004

12. Chiosis G, Vilenchik M, Kim J and Solit D: Hsp90: The vulnerable chaperone. Drug Discov Today 9: 881-888, 2004.

13. Mosser DD and Morimoto RI: Molecular chaperones and the stress of oncogenesis. Oncogene 23: 2907-2918, 2004.

14. Whitesell L, Mimnaugh EG, De Costa B, Myers CE and Neckers LM: Inhibition of heat shock protein HSP90-pp60v-src heteroprotein complex formation by benzoquinone ansamycins: Essential role for stress proteins in oncogenic transformation. Proc Natl Acad Sci USA 91: 8324-8328, 1994.

15. Trepel J, Mollapour M, Giaccone G and Neckers L: Targeting the dynamic HSP90 complex in cancer. Nat Rev Cancer 10: 537-549, 2010 . 
16. Supko JG, Hickman RL, Grever MR and Malspeis L: Preclinical pharmacologic evaluation of geldanamycin as an antitumor agent. Cancer Chemother Pharmacol 36: 305-315, 1995.

17. Caldas-Lopes E, Cerchietti L, Ahn JH, Clement CC, Robles AI, Rodina A, Moulick K, Taldone T, Gozman A, Guo Y, et al: Hsp90 inhibitor PU-H71, a multimodal inhibitor of malignancy, induces complete responses in triple-negative breast cancer models. Proc Natl Acad Sci USA 106: 8368-8373, 2009.

18. Lundgren K, Zhang H, Brekken J, Huser N, Powell RE, Timple N, Busch DJ, Neely L, Sensintaffar JL, Yang YC, et al: BIIB021, an orally available, fully synthetic small-molecule inhibitor of the heat shock protein Hsp90. Mol Cancer Ther 8: 921-929, 2009.

19. Bao R, Lai CJ, Wang DG, Qu H, Yin L, Zifcak B, Tao X, Wang J, Atoyan R, Samson M, et al: Targeting heat shock protein 90 with CUDC-305 overcomes erlotinib resistance in non-small cell lung cancer. Mol Cancer Ther 8: 3296-3306, 2009.

20. Woodhead AJ, Angove H, Carr MG, Chessari G, Congreve M, Coyle JE, Cosme J, Graham B, Day PJ, Downham R, et al: Discovery of (2,4-dihydroxy-5-isopropylphenyl)-[5-(4-methylpiperazin-1-ylmethyl)-1,3-dihydrois oindol-2-yl]methanone (AT13387), a novel inhibitor of the molecular chaperone Hsp90 by fragment based drug design. J Med Chem 53: 5956-5969, 2010

21. Wang Y, Trepel JB, Neckers LM and Giaccone G: STA-9090, a small-molecule Hsp90 inhibitor for the potential treatment of cancer. Curr Opin Investig Drugs 11: 1466-1476, 2010.

22. Eccles SA, Massey A, Raynaud FI, Sharp SY, Box G, Valenti M, Patterson L, de Haven Brandon A, Gowan S, Boxall F, et al: NVP-AUY922: A novel heat shock protein 90 inhibitor active against xenograft tumor growth, angiogenesis, and metastasis. Cancer Res 68: 2850-2860, 2008.

23. Ohkubo S, Kodama Y, Muraoka H, Hitotsumachi H, Yoshimura C, Kitade M, Hashimoto A, Ito K, Gomori A, Takahashi K, et al: TAS-116, a highly selective inhibitor of heat shock protein 900 and $\beta$, demonstrates potent antitumor activity and minimal ocular toxicity in preclinical models. Mol Cancer Ther 14: 14-22, 2015.
24. Bussenius J, Blazey CM, Aay N, Anand NK, Arcalas A, Baik T, Bowles OJ, Buhr CA, Costanzo S, Curtis JK, et al: Discovery of XL888: A novel tropane-derived small molecule inhibitor of HSP90. Bioorg Med Chem Lett 22: 5396-5404, 2012.

25. Infante JR, Weiss GJ, Jones S, Tibes R, Bauer TM, Bendell JC, Hinson JM Jr, Von Hoff DD, Burris HA III, Orlemans EO and Ramanathan RK: Phase I dose-escalation studies of SNX-5422, an orally bioavailable heat shock protein 90 inhibitor, in patients with refractory solid tumours. Eur J Cancer 50: 2897-2904, 2014.

26. Jeong JH, Oh YJ, Lho Y, Park SY, Liu KH, Ha E and Seo YH: Targeting the entry region of Hsp90's ATP binding pocket with a novel 6,7-dihydrothieno[3,2-c]pyridin-5(4H)-yl amide. Eur J Med Chem 124: 1069-1080, 2016.

27. Jeong CH, Park HB, Jang WJ, Jung SH and Seo YH: Discovery of hybrid Hsp90 inhibitors and their anti-neoplastic effects against gefitinib-resistant non-small cell lung cancer (NSCLC). Bioorg Med Chem Lett 24: 224-227, 2014

28. Jeong JH, Oh YJ, Kwon TK and Seo YH: Chalcone-templated Hsp90 inhibitors and their effects on gefitinib resistance in non-small cell lung cancer (NSCLC). Arch Pharm Res 40: 96-105, 2017.

29. Dai C and Sampson SB: HSF1: Guardian of proteostasis in cancer. Trends Cell Biol 26: 17-28, 2016.

30. Dechow TN, Pedranzini L, Leitch A, Leslie K, Gerald WL, Linkov I and Bromberg JF: Requirement of matrix metalloproteinase-9 for the transformation of human mammary epithelial cells by Stat3-C. Proc Natl Acad Sci USA 101: 10602-10607, 2004. 